\title{
The Graduate Helper: Using a Mobile Application as a Feasible Resource for Job Hunting Across Saudi Arabia
}

\author{
https://doi.org/10.3991/ijim.v12i4.7566 \\ Maram Meccawy $\left.{ }^{\square}\right)$, Amani Alalasi, Deemah Alsaud, Maha Alamoudi, \\ Mashael Alessa, Muneera Alyami and Nuha Alsheikh \\ King Abdulaziz University, Saudi Arabia \\ mmeccawy @ kau . edu. sa
}

\begin{abstract}
Graduates and senior university students are filled with ambitions; they are very close to fulfilling their dreams by joining the workforce. However, finding their targeted job is a cumbersome and often tedious task. Moreover, some of those graduates' lack certain necessary skills that qualify them for the labor market. Hence, they might want to overcome this problem by taking some training courses to increase their chances in securing that soughtafter job. Graduate Helper, is a mobile application for seeking employment opportunities in Saudi Arabia. It focuses on recent graduates in the Kingdom. The successful implementation of Graduate Helper received an appreciation from graduates, who used it for their job hunts.
\end{abstract}

Keywords-Graduates Job Search, Mobile Applications, Feasible Resource, Saudi Arabia

\section{Introduction}

Global economy has encountered substantial challenges during 2009 till date. According to the current global situation, 73 million young graduates have urged to get employment opportunities [1]. The incidence of such challenges has resulted in recession related complications across the globe. Currently, an individual seeks for suitable job opportunities via broadcasting media such as, television, newspaper, and radio. This study has focused on an appropriate mobile application, which would exclusively be developed for the graduates to search suitable opportunities for their career development across Saudi Arabia. This application was named as the "Graduate Helper", which provides an electronic guide for the graduates related to their career.

Career development has always been a significant issue across the globe. Since career portrays an impactful effect on the lives of people; therefore, decision making regarding career and jobs is one of the sensitive tasks [2]. Vocation of a person depicts status and personality of an individual either socially or economically. Choosing a career includes several distinct factors, which mainly include how much time a person can offer to his family, which place he would choose to live in, and how much time he gets to perform his social or leisure activities. Therefore, such elements 
should be considered while seeking any opportunity. Alternatively, it was observed that youth was more probable to be jobless as compared to the adults [3].

Another media used for the achievement of this particular task of job hunting is internet and social media. The only drawback attached with the use of internet is that the individuals often feel insecure while updating their authentic data [4]. Mobile applications and its usage has been spreading worldwide with a highly increasing ratio. $92 \%$ of the youth has access to cellular phones all over the globe [5]. The world is moving towards the adaptation of latest technologies steadily. Adoption and preference of mobile applications as compared to desktop applications have been resulted because of accessibility. Mobile phone is the portable form of technology; therefore, it bares high importance. Individuals can conduct their routine activities with the use of mobile phones quite effortlessly. Online services have been reached to the maximum usage across Saudi Arabia [6]. The Saudi government has motivated such services due to its effective application. The resources, retrieved through the use of mobile computation, have been contributed in the development of Saudi economy. However, the literature related to such information is limited. A study was conducted to spread the importance of mobile computation and to understand the trends and status among Saudi domains [4]. Thus, the basic aim of the study is to help Saudi graduates to find better job opportunities with the use of mobile application.

Many students have faced problems in regards of employment opportunities at the fresh graduate level [7]. Multiple methods have been enforced by several higher education organizations to provide their students with experience at the intern level at least to flourish their careers [6]. It has been reported by Central Department of Statistics and Information that the rate of unemployment is $12.1 \%$ in Saudi Arabia [8]. The reason behind such dilemma is that there is believed to be a wide difference between labor market and local graduates as claimed by the private sector. Also, another issue is the lack of a central hub for job hunting.

Young graduates have an urge to seek the most feasible opportunity, which would also help them to enrich their career goals. However, the trends of recession along with inappropriate financial activities have resulted in reduced level of employment opportunities. In Saudi Arabia, English language has been identified as a common problem, which usually affects the decision making and employment searching processes. Most of the online sites for job offers are developed in English language. Therefore, majority of the graduates are unable to understand the core aspects, related with applying for jobs through online portals. In order to address these issues, Graduate Helper, an electronic guide was developed to help graduates find available jobs according to their qualifications and expertise. Moreover, this guide would be helpful to list the training courses applicable in the labor market for such category of the job.

\section{Related Work}

Substantial researches have been conducted to provide improved solutions for the job searching criteria. One of the studies suggested a solution by using fuzzy preference rules in making decisions in accordance with the users' choice. To provide the 
user friendly and robust application, this system used ANDROID 2.2, Google API, and JADE-LEAP [9]. Another study has developed the job clusters, which showed the relationship between the company needs and the professionals. As a result, the visualization of the network was created between the companies and professions [10].

Another research provided a multi-agent system, which has focused on the time consuming task of job searching. This system proposed job match-making in teleworking community [11]. Furthermore, a semantic web-based research was conducted [12] to provide a solution for data exchange between applicants, job portals, and job employers. Dictionary was created by this study to build the ontology related with industrial sectors, occupations, and job skills.

Two-sided model approach has been identified, in which workers' cost of application has been explained, which was helpful in growing the job search on internet [13]. Moreover, the study evaluated that search models of basic worker side, which are used to lower search costs. This study characterized workers as the privately known agents of the firm specific productivity. The findings indicated that lowered search costs help in improvising job search. Another approach evaluated that a job application can be received at the computer server system in the form of SMS (Short Messaging Service) [14]. This application is sent by the job seeker device, which is operating independently on the computer system.

It has been observed by the aforementioned studies that job hunting models require several time models to search the unemployed worker's behavior. Moreover, it requires user friendly interface with less complexities. The traditional mediums are mainly used by the job marketing, newspaper advertising, and recruitment agencies. Whenever a company needs to recruit employees within a shorter period, they usually use local newspapers or international newspapers for publishing their ads. Recruitment agencies, on the other hand, compared the skills of the candidates with the required skill set of the company [15]. In the current era, the fastest medium to apply for the job is internet. Therefore, there have been multiple websites that exists to seek job opportunities. These websites promote careers and employment vacancies to the users so that they can post their resumes online. Some of the websites that are commonly used for job seeking purpose in Saudi Arabia, including Bayt.com, Khbrah.com, and Wadhefa.com. There are also some mobile applications that are made to list job vacancies. These applications include Careerjet, Bayt, and MonsterApp. Jobs vacancies are also present across the social media, which include Facebook, Twitter, and LinkedIn. These web and mobile applications carry considerable fame and has been proven quite successful in the job hunting procedures.

\section{Proposed System}

The software design is considered as the significant step for the progress of system. A system has been proposed to illustrate the simple description and design of the application. Graduate Helper provides firstly with the home page and provides different options, including training courses, finding a job, create your resume, interview skills, notices, profile, ask for help, and information about us in Arabic language for 
the users of Saudi Arabia. The page of search for job allows the user to enter their specialization, name of the company, and job title to assist the users for finding job. Results for the job search are presented on the screen by clicking on the search. Practical experience is also asked by the application to assist more in searching a job. The information is saved by the application automatically. Help messages to administration can also be easily sent by the user. Home page saves the tasks performed by the users regarding the job search. The 'Show Jobs Page' of the application displays all the jobs related to the information posted by the user. An account by the user is required, which provides a sign-up option to create a new account. Logging into the account enables the users to view their profile and job searches. An option of 'Edit' has also been provided, which enables the user to edit their information, saved previously. The admin of the application will be provided with a special user name and password to access the admin view. Graduate Helper also allows company to create an account so that the user may approach the desired company.

Graduate Helper is capable of providing the features such as job searching, course searching, writing resumes and experiences, and the interactive user profile. One of the distinct features provided by the Graduate Helper is the course search that makes it different from the other websites and mobile applications. Therefore, Graduate Helper was developed to cater all the requirements of the Saudi graduates in regards of job hunting. Graduate Helper is an electronic guide, which helps in searching jobs and related courses of the particular job domain asked by the user. The front end of Graduate Helper was built up using HTML, CSS, and JavaScript. Front-end bares features such as drop-down menus, sliders, transitions, buttons, fonts, registration forms, and contact forms. The back-end development of Graduate helper was performed using C\# and JavaScript along with the databases. As the user is signed up, he/she is asked to fill up the registration form by providing all the necessary details required for job searching. This information is stored in the database controlled by the server. Server-side functionality was performed using bringster.com and was the most complicated tasks to be carried out during the implementation of the application. Linking of database was done with the front-end to provide users updated information and display it on the user interface.

Managing resumes is another process performed by the Graduate Helper. In this process, the user presses the 'Write Resume' button prompt on the screen and starts to write the resume, system stores the resume and provides the user with a form that asks general questions about the educational and professional skills. On the completion of this form, the system stores all the information in the database. Profile management is another procedure, in which user can have the facility to edit his/her profile in accordance with his updated information. 'Request Help' is another button present on the UI (User Interface) of the application. This feature would help the user to view sample forms to take guide in creating his profile. Verification of the Account is performed by the admin. The passwords and IDs provided by the user while logging into the profile, the database will match the newly entered information with the previous stored data. If the data is matched, then the access would be provided to the user to view his profile. Jobs and courses are uploaded by the companies on the application and the users can view it from the application 
The user interface Graduate Helper is provided, so that it would be easy to understand the major functionalities of the application. There are three vital entities that would use Graduate Helper, 1) Job-seeker, 2) Admin, and 3) Company. Registration process will be conducted in two steps; 1) user fills the registration form, 2) if the filling of form was done successfully, then the jobs and courses start to appear at the users' screens. Searching process takes place in three levels; 1) user enters the related keywords for the particular job or course, 2) the application searches for the entered keywords, and 3) the results will be displayed to the users. Search for Job page, Help page, login page for Admin, Signup page for Company and User page have been shown in Figure 1, 2, 3, 4 and 5 respectively.

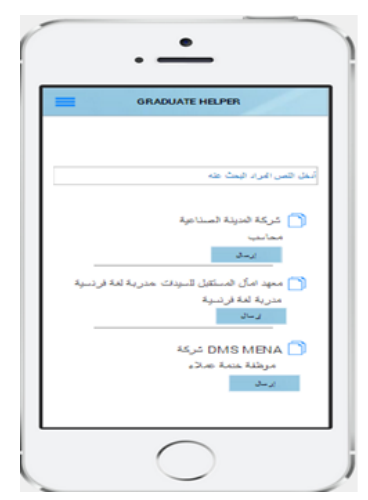

Fig. 1. Search for Jobs Page

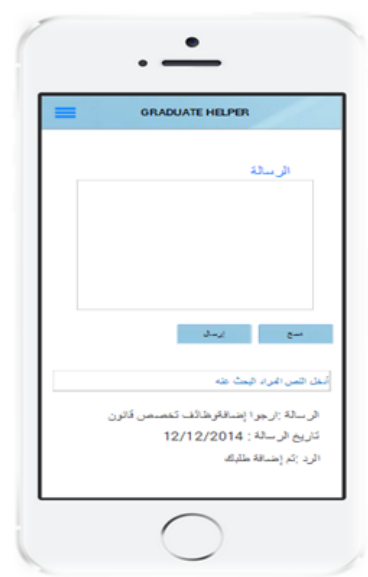

Fig. 2. Help 


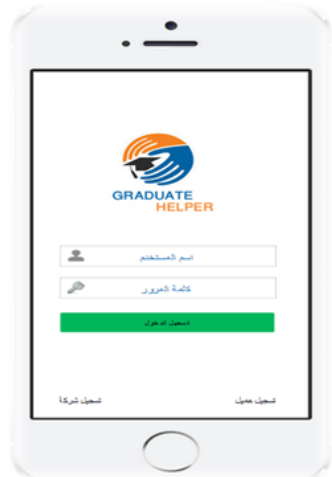

Fig. 3. Graduate Helper's Login Page

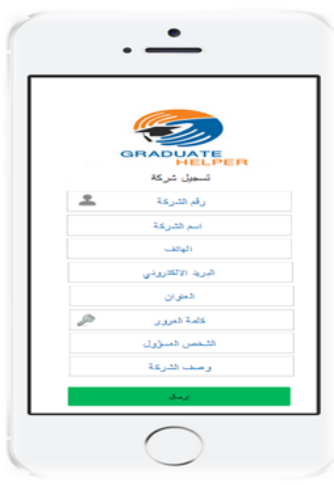

Fig. 4. Sign up Page for the job listing by a Company

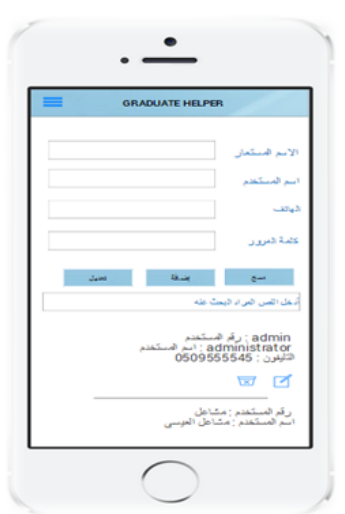

Fig. 5. User Page 


\subsection{Functioning of the Model}

The common functionality of the model comprises of certain steps, which include register, log-in, search for jobs, search for courses, write resume, update resume, send resume, help users, add users, delete users, view user profile, edit user profile, request help, logout, upload courses, and upload jobs. All these steps are effective for the proper functioning of model.

\section{$4 \quad$ Methodology}

Primary qualitative analysis was conducted by interviewing 10 respondents to understand the need for employment among the graduates, and the development of employment application. 6 out of 10 respondents reported that they find hard to search for a job online. 7 out of 10 respondents recommended making the design of the application a bit easier and helpful. 10 out of 10 respondents were eager to be acquainted with the new jobs addition. 4 out of 10 respondents said that they needed to get information about the updates in the application via emails and equal number of respondents reported that the notifications should be appeared on their home pages. In order to become the permanent users of the application, 5 out of 10 respondents asked to add the periodic update feature. The questionnaire was also distributed online and was responded by 20 individuals. Some of the requirements were divided into two forms, non-functional and functional requirements. Functional requirements included the services, which an application should perform at any cost. Non-functional requirements included platform, quality, and technical requirements. The application was developed in four phases; designing phase, implementation phase, testing phase, and evaluation phase.

\section{$5 \quad$ Results}

The features and options of Graduate Helper application were examined by developing a plan to get useful conclusion. A comfortable environment was provided to the users to find the quality and efficiency of the application. In order to evaluate the results of the study, the functional testing phase was conducted. The functional tests efficiently defined the working system in a useful manner. It has been observed that the general performance was accepted for every task concerning the average time required to complete a particular task. Furthermore, the usability of the system has been evaluated to measure the ease of using application. It assisted to examine the errors in the design that hinders while using the application. Real users were recruited, who tested Graduate Helper Application to discover the complications faced in the real-world settings. The opinions and suggestions were recorded by using a questionnaire. Table 1 represents Graduate student task time according to their name and performance. 
Table 1. Results of the usability test

\begin{tabular}{|l|c|}
\hline \multicolumn{1}{|c|}{ Measures } & Percentage \\
\hline Clear Application & $85 \%$ \\
\hline Users like to use application again & $71 \%$ \\
\hline Buttons were well organized and easy to find & $71 \%$ \\
\hline Users like colour of application & $57 \%$ \\
\hline Design for data entry is flexible & $86 \%$ \\
\hline Application is simple to use & $100 \%$ \\
\hline It is easy to learn how to use the application & $86 \%$ \\
\hline The application gives them error messages that clarify how to fix problem. & $86 \%$ \\
\hline
\end{tabular}

Table 1 showed the results of the usability test that were taken to check the errors while using the application. It has been observed that all of the users found it easy and simple to use $(100 \%)$ and majority of the users were interested to use the application again $(71 \%) .85 \%$ of the users found the application clear and $71 \%$ believed that buttons were well organized and easy to find. Design for the data entry was also appreciated by the users $(86 \%)$. The error messages were received by the users that clarifies the way to fix the problem $(86 \%)$. While the color of application was not much liked by the users, as only $57 \%$ of the users liked the color of the application.

\subsection{Designing Phase}

Since, the most interactive interfaces grasp higher attention of individuals; therefore, it is significant to use interactive deigns, while developing an application. The software design of the Graduate Helper incorporated user interface, admin interface, and company interface.

\subsection{User Interface}

User Interface contains a home page, which have certain features that may include search training courses, find a job, interview skills, create your resume, ask for help, information about us, and user profile. 'Search for jobs' offers features like job title, name of a company, and specialization for a user. 'Search' button is then clicked by the user to view the results generated after the entered keywords. 'Search for courses' allow users to hunt for the courses related to the employments. 'Create your resume' page offers features, Practical experiences, education, communication information, and training courses. 'Show resume' display the uploaded resume to the user. Users enter information related to their letter of thanks and practical experiences in the form. After entering all of the details, the user clicks the button 'Next', this will save all the information entered by the user into the database. Help page allows the users to send help message to the admin. 


\subsection{Admin Interface}

The admin interface is related with home page that is accessible to the admin only. The admin can perform tasks such as add courses, add jobs, display the users, display the jobs, and display the courses. 'Add jobs' provide admin with the facility to mobilize all data that is required to be added related to the jobs. 'View jobs' list all the jobs that have been uploaded by the companies.

\subsection{Company Interface}

The company interface allows the users to add company name, name of a person in charge, email address, residential address, contact numbers, password. After entering all these details, the user presses the button 'save' to store the personal information in the database. Home page of the company interface acquires features such as add jobs, manage profile, view users' CVs, and add courses. As the person in charge clicks the 'edit' button, he can edit all the information written already. 'Add jobs' page displays every job posted by that company and is editable too. 'Add course' page obeys the similar design used by the 'Add jobs'.

\subsection{Database Design}

The database of the Graduate Helper contained six tables. These tables were entitled as the User table, Company table, Admin table, Company_Course Table, User_Job table, Company_Job table, Cedrtificate table, and the Experience table.

\subsection{Implementation Phase}

Implementation phase is referred as the coding phase, in which all the back-end development is carried out. The final product is developed in this phase by incorporating the design of the application with the back-end development. Development environment provided by the Graduate Helper used some languages and tools. Microsoft Visual Studio 2010 was used by the application as a designing tool. Microsoft SQL Server was used for the database management that is developed by the Microsoft; C\# was used as a programming language also known as object-oriented, general purpose programming language. The front-end development used JavaScript and JQuery, and ASP.net was used for the back-end development. PhoneGap is the software used by the application to convert C\# into APK (Android Application Package) for the application.

\subsection{Testing Phase}

To test the ease of system, usability test is usually conducted, which is helpful in the discovery of errors in the software design. The application was tested on the genuine users by assigning some tasks. Functionality testing was used to incorporate all the needs of users and its validity with the application. Task times were allotted and 
the results of these times were calculated on the basis of the time taken by the Users, Admin, and Company. In addition to it, an environment setup is prepared to test the validity of the application. Testing equipment mainly includes smart phones and the computers. Multiple devices were used to test the compatibility of the device on each system. Test plan included bringing the users to the testing environment and giving them the authority to explore anything regarding the application by observing them remotely. All the observations were performed on them while they were conducting the tests. Functionality testing was then performed by ensuring that the features of application were either performing accurately or not. A number of bugs occurred during the testing which can be listed down. Furthermore, the results were calculated on the basis of the questions, which are asked from the respondents. On the functionality basis, $86 \%$ respondents reported that the application was performing correctly as per its functionality. $72 \%$ of the users were satisfied with the amount of jobs present on the application. $85 \%$ of the users reported that application was very clear and easy to use. $71 \%$ of the 14 users showed their interests in using the application again. $71 \%$ of the users reported about the user interface, that it was well organized and quite presentable. $57 \%$ of the users liked the colour of the application. $86 \%$ of 14 users informed that the design of the application was very flexible. $100 \%$ users have found the application easier to be used. $86 \%$ felt that it was easy to learn the steps followed by the application. $86 \%$ also said that if any problem was encountered in the application, they were provided with the fixing mechanism immediately.

Interviewers and students were observed facing some limitations during the test. The users were afraid or confused to download the application in their mobiles and wanted to use the developer device. The process took enough time as there were not enough devices. Due to the lack of Windows mobiles, the test was taken on Android phones. It has been observed that Graduate Helper has no alert notifications; whereas, other website/mobile application has alert notifications. User Profile, Job search and Course Search are the options provided by Graduate Helper and other applications as well. Whereas, there is no option for sending an email in the proposed application.

\section{Discussion}

The results of the study have shown that Graduate Helper passed through different stages from analyzing and selecting ideas until the final evaluation has been done. The application has successfully been proven to assist the users in job hunting process. The usability test has suggested that application is capable enough to support the users and provides an easy and friendly way to search a job. The study has aimed to propose a system that may assist the job seekers in Saudi Arabia in their job hunting process in their own language. The language issues may be one of the hindrances in the way of searching a job by a graduate. So, the study intended to propose a system that may enhance the job possibilities of a graduate and helps to easily search a job.

Individuals have been seeking for the employment opportunities through social media since a long period [16]. They uploaded their resumes on the job portals, exchange their personal details of experience with the employers, and surf impending 
employers' websites via internet [17]. Mobility of job and free movement have become essential factors in the modern times. Therefore, multiple mobile applications such as Bayt.com, Monsterapp, and Careerjet etc. have been developed to overcome this necessity, as discussed in the previous sections.

Bayt.com provides users with the search and apply feature for jobs along with the feature of editing their profiles. It has been available in several languages, including Arabic. The limitations to bayt.com are that it does not provide course services and do not show full job descriptions [18]. Monsterapp was designed for the Android devices and is a job searching application. This application granted users to view, search, and apply for jobs. Moreover, Monsterapp generates alert message notifications for the ease of the users. The limitations attached to the Monsterapp includes users cannot build resumes and cover letters, and cannot update, delete, and view their profiles and CVs anytime they desire. This application is currently based on the English language [19]. Careerjet has the features of searching and applying too. It sends jobs via emails and helps user to manage the profile [20].

M-learning or the mobile learning has gained popularity as an online learning channel. Practitioners and academics are also interested in evaluating its capability to encourage and support online learning [21]. However, previous studies have focused on the challenges in supporting m-learning adoption [22-25]. The existing m-learning literature has mainly highlighted the technology related variables to observe the adoption of m-learning. Although, few studies have determined this topic from the motivation of user's perception and fewer from the context of adult learner [26, 27]. The rapid development of communication and information is transforming the picture of how learning can be delivered to students. ICT has been extensively used as an alternate means to traditional face-to-face interaction among the students and job seekers $[25,28]$. The mobile learning allows the graduates to interact online as the adoption of m-learning is influenced positively by the user's attitude. Online learning also allows the users to have more chances of searching a job.

Digital recruiting process has become a significant element of attracting, recruiting and sourcing the top talent $[29,30]$. The quality of life services 'Sodexo' in the USA has 125,000 employees. It has earlier adopted the use of social media and launched a mobile application that allows the candidates to apply for the desired job from their mobile application directly. The company has identified the cultural modification in favored communication techniques by job candidates [30].

Mobile or handsets have grown up, and the smartphones applications have dragged it into a technological advancement to drive into the future [31, 32]. Mobiles are becoming sophisticated and easier to use increasingly [33]. The cloud computing has enhanced the handsets to permit extremely complicated interface and to offer users with strong mobile experience [34]. The current study has kept its focus on the objective of building an application, which displays job vacancies and opportunities to the fresh graduates in Saudi region. Application developed in this study is distinct from the previous applications in a way that it presents graduates with the list of courses they might require to get admission in the specific companies. The application was exclusively designed for the Arab graduates who find it difficult to understand English. This application was developed in the Arabic language along with the English 
contents. It has been observed that Graduate Helper was appreciated by most of the students and they found it quite easy to handle.

\section{Conclusion}

The applications for job searching have been spreading world-wide with enhanced features and facilities for the users. Unfortunately, these sites are mostly English language based. English is not the first language for Saudi graduates; therefore, it became significant for the new researchers to invent an Arabic application. This study developed an application named "Graduate Helper", which provided an electronic guide to the graduates for their job hunt. The application offered courses and their training in accordance with the labor market demands to get students prepared for the desired companies. Usability tests were applied to the application to test its functions' accuracy. Future recommendations include making this application compatible with the IOS platform and hence increasing its user base. In addition, to be made available for the other Arab countries.

\section{Acknowledgement}

The authors are very thankful to all the associated personnel in any reference that contributed in/for the purpose of this research.

\section{References}

[1] Bogle S, Sankaranarayanan S. (2012) Job Search System In Android EnvironmentApplication Of Intelligent Agents. International Journal of Information Sciences and Techniques (IJIST). 2(3). https://doi.org/10.5121/jist.2012.2301

[2] Super, D.E., (1990). A life-span, life-space approach to career development. https://doi.org/10.1016/0001-8791(80)90056-1

[3] Anderson, D., Chen, F. and Schroeder, K., (2013). Innovation and Technology for Youth Employment.

[4] Alotaibi, M.B., 2015. Mobile computing trends in Saudi Arabia: An exploratory study. computing, 8, p.9. https://doi.org/10.5815/ijitcs.2015.01.03

[5] Dawes, L.A.U.R.E.N. and Marom, R., (2013). Mobile Services for Youth Employment. Hong Kong, Slide Presentation. GSMA and Alcatel-Lucent.

[6] Helyer, R. and Lee, D., (2014). The role of work experience in the future employability of higher education graduates. Higher Education Quarterly, 68(3), pp.348-372. https://doi.org/10.1111/hequ.12055

[7] Central department of statistic and information. (2013). "Unemployment rate". Retrieved from http://www.cdsi.gov.sa/

[8] Frivolt, G. and Bieliková, M., (2006). Improving Job Search by Network of Professions and Companies. Bratislava, Slovakia: Institute of Informatics and Software Engineering. https://doi.org/10.1109/COGINF.2003.1225971 
Paper-The Graduate Helper: Using a Mobile Application as a Feasible Resource for Job Hunting ...

[9] Mochol, M., Wache, H. and Nixon, L., (2007). Improving the accuracy of job search with semantic techniques. In International Conference on Business Information Systems(pp. 301-313). Springer, Berlin, Heidelberg. https://doi.org/10.1007/978-3-540-72035-5 23

[10] McKenzie, L., (2015). Internet job search: A two-sided search model approach.

[11] Cate, M.S., Regallis, J.D., Orth, G., Goldstein, T. and Caldwell, D., FLEXHIRE LLC, (2014). Computer based job application via SMS message or mobile email. U.S. Patent $8,682,806$.

[12] J. Nielsen and R. L Mack. (1994). "Usability Inspection Methods John Wiley \& Sons. New York".

[13] Green, A.E., De Hoyos, M., Li, Y. and Owen, D., (2011). Job search study: Literature review and analysis of the Labour Force Survey. Department for Work and Pensions Research Report, 726.

[14] Bayt.com. (2014). Retrieved. May 6. Retrieved from https://play.google.com/store/ apps/details?id=com.Bayt

[15] Monster Application. (2014). Retrieved May.6. From https://play.google.com/store/apps/ details?id=com.monsterindia.seeker.views

[16] Google Inc. (2012) "Case Study: Careerjet increases traffic and improves usability through a new mobile website".

[17] J. P. Sampson \& D.S Osborn. (2015) "Using information and communication technology in delivering career interventions". APA handbook of career intervention. 2:57-70. https://doi.org/10.1037/14439-005

[18] Hargittai, E. and Marwick, A., (2016). "What can I really do?" Explaining the privacy paradox with online apathy. International Journal of Communication, 10, p.21.

[19] Carrascal, J.P. and Church, K., (2015), April. An in-situ study of mobile app \& mobile search interactions. In Proceedings of the 33rd Annual ACM Conference on Human Factors in Computing Systems (pp. 2739-2748). ACM.

[20] Saks, A.M., Zikic, J. and Koen, J., (2015). Job search self-efficacy: Reconceptualizing the construct and its measurement. Journal of Vocational Behavior, 86, pp.104-114. https://doi.org/10.1016/j.jvb.2014.11.007

[21] Hashim, K.F., Tan, F.B. and Rashid, A., (2015). Adult learners' intention to adopt mobile learning: A motivational perspective. British Journal of Educational Technology, 46(2), pp.381-390. https://doi.org/10.1111/bjet.12148

[22] Morris, T.A., (2009). Anytime/Anywhere Online Learning: Does It Remove Barriers. Online Education and Adult Learning: New Frontiers for Teaching Practices: New Frontiers for Teaching Practices, p.115.

[23] Park, S.Y., Nam, M.W. and Cha, S.B., (2012). University students' behavioral intention to use mobile learning: Evaluating the technology acceptance model. British Journal of Educational Technology, 43(4), pp.592-605. https://doi.org/10.1111/j.1467-8535.2011.01229.x

[24] Petrova, K. and Li, C., (2009). Focus and setting in mobile learning research: A review of the literature.

[25] Ryu, H. and Parsons, D., (2009). Designing learning activities with mobile technologies. IGI Global, 4, p.20.

[26] Huang, J.H., Lin, Y.R. and Chuang, S.T., (2007). Elucidating user behavior of mobile learning: A perspective of the extended technology acceptance model. The Electronic Library, 25(5), pp.585-598. https://doi.org/10.1108/02640470710829569

[27] King, K.P., (2002). Testing the Waters for Distance Education in Adult Education Programs. PAACE Journal of Lifelong Learning, 11, pp.11-24. 
Paper-The Graduate Helper: Using a Mobile Application as a Feasible Resource for Job Hunting ...

[28] Liu, Y., Han, S. and Li, H., (2010). Understanding the factors driving m-learning adoption: a literature review. Campus-Wide Information Systems, 27(4), pp.210-226. https://doi.org/10.1108/10650741011073761

[29] Melanthiou, Y., Pavlou, F. and Constantinou, E., (2015). The use of social network sites as an e-recruitment tool. Journal of Transnational Management, 20(1), pp.31-49. https://doi.org/10.1080/15475778.2015.998141

[30] Ball, A., Freshwater, T. and Valderrama, S., (2015). Human Resources Marketing and Recruiting: Digital Recruiting at Sodexo. Handbook of Human Resources Management, pp.19.

[31] Zhang, M.W., Tsang, T., Cheow, E., Ho, C.S., Yeong, N.B. and Ho, R.C., (2014). Enabling psychiatrists to be mobile phone app developers: insights into app development methodologies. JMIR mHealth and uHealth, 2(4). https://doi.org/10.2196/mhealth.3425

[32] Lamm, C., Lambert, L., Wolfe, J., Gray, J., Barber, A. and Edwards, G., (2014). Improving Socialization and Emotion Recognition for Children with Autism Using a Smartphone App. In Innovative Technologies to Benefit Children on the Autism Spectrum (pp. 125142). IGI Global. https://doi.org/10.4018/978-1-4666-5792-2.ch008

[33] Y. Yan, S Xiong, X Lou, H Xiong, Q Miao. (2014). "Design and implementation of educational administration information access system based on android platform". InFrontier and Future Development of Information Technology in Medicine and Education. (pp. 2525-2533). Springer Netherlands.

[34] Rittinghouse, J.W. and Ransome, J.F., (2016). Cloud computing: implementation, management, and security. CRC press.

\section{Authors}

Dr. Maram Meccawy, Amani Alalasi, Deemah Alsaud, Maha Alamoudi, Mashael Alessa, Muneera Alyami, and Nuha Alsheikh are with King Abdulaziz University, Saudi Arabia.

Article submitted 10 August 2018. Resubmitted 14 May 2018. Final acceptance 08 August 2018. Final version published as submitted by the authors. 